\title{
Two new species of Ripella (Amoebozoa, Vannellida) and unusual intragenomic variability in the SSU rRNA gene of this genus
}

\author{
Alexander Kudryavtsev ${ }^{\mathrm{a}, *}$, Anna Gladkikh ${ }^{\mathrm{a}, \mathrm{b}}$ \\ ${ }^{a}$ Department of Invertebrate Zoology, Faculty of Biology, Saint-Petersburg State University, 199034 Saint-Petersburg, Russia \\ ${ }^{\mathrm{b}}$ Irkutsk Antiplague Research Institute of Siberia and Far East, 664047 Irkutsk, Russia
}

Received 3 June 2017; received in revised form 22 August 2017; accepted 8 September 2017

Available online 14 September 2017

\begin{abstract}
Two new species, Ripella decalvata and R. tribonemae (Amoebozoa, Vannellida), are described and the diversity of known strains assigned to the genus analyzed. Ripella spp. are closely similar to each other in the light microscopic characters and sequences of small-subunit (SSU) ribosomal RNA gene, but differences in the cell coat structure and cytochrome oxidase (COI) gene sequences are more prominent. SSU rRNA in $R$. platypodia CCAP1589/2, R. decalvata and $R$. tribonemae demonstrates an unusual pattern of intragenomic variation. Sequencing of multiple molecular clones of this gene produced numerous sequence variants in a number of specific sites. These sites were usually terminal parts of several variable helices in all studied strains. Analysis of all known Ripella strains shows that SSU rRNA sites differing between strains of different origin are mainly restricted to these areas of the gene. There are only two sites, which differ between strains, but not within genomes. This intragenomic variability of the SSU rRNA gene, seemingly characteristic of all Ripella spp., was never reported to be so extensive in Amoebozoa. The data obtained show another example of complex organization of rRNA gene cluster in protists and emphasize caution needed when interpreting the metagenomic data based on this marker.
\end{abstract}

(C) 2017 Elsevier GmbH. All rights reserved.

Keywords: Amoebozoa; Molecular phylogeny; Ripella; rRNA; Taxonomy; Vannellida

\section{Introduction}

The genus Ripella was first established by Smirnov et al. (2007) within the family Vannellidae, however its first member was described more than a century ago. Initially, the species was named Amoeba platypodia (Gläser 1912). It was later transferred into a newly created genus Vannella (Bovee 1965), however, this point of view was not unanimously supported, as Page (1968) first included this species in the genus

\footnotetext{
${ }^{*}$ Corresponding author.

E-mail address: alexander.kudryavtsev@spbu.ru (A. Kudryavtsev).
}

Flabellula, and only later (Page 1976) started to consider it to be a member of Vannella. This amoeba was considered to be typical yet small freshwater Vannella due to its glycocalyx represented by the pentagonal glycostyles and simple filaments (Page and Blakey 1979), a typical star-shaped floating form with tapering pseudopodia and the change of direction of locomotion by formation of the two temporary parts of the frontal hyaline area moving in opposite directions (summarized in Page 1983). The molecular investigations of the family Vannellidae demonstrated that Vannella platypodia formed a long, deeply branching clade within the Vannellidae together with several unnamed isolates, and a separate genus 
Ripella was established to accommodate it (Smirnov et al. 2007). Unfortunately, too few members of this genus have been morphologically characterized until now. In spite of the presence of 5 unnamed isolates within a clade corresponding to Ripella (Dyková et al. 1996, 2005, 2010; Dyková and Kostka 2013), the genus has been remaining formally monotypic until now, and its diagnosis was mainly based on the characters of $R$. platypodia. Therefore, it contains very few differentiating morphological details, and outlines the group most reliably based on small-subunit ribosomal RNA gene sequence characteristics. In particular, it has been shown that members of the genus have an unusually short SSU rRNA gene with a number of deletions (Smirnov et al. 2007).

The purpose of this paper is to describe two new Ripella species and analyze unusual pattern of variability in their small-subunit (SSU) ribosomal RNA gene, which seems to be characteristic for the whole genus.

\section{Material and Methods}

\section{Amoebae isolation, culturing and microscopy.}

Three strains of Ripella were investigated during this study: (1) $R$. platypodia CCAP $1589 / 2$ originally isolated by F.C. Page (Page 1968); (2) R. decalvata n. sp. Negev 3$2 \mathrm{c}$, isolated from a sample of bottom sediment picked from the freshwater habitat in Ein Yorke' am (Negev desert, Israel; N30.938562 E35.04087) in 2011; (3) R. tribonemae n. sp. SK1 isolated from the culture of a green alga Tribonema sp. kindly provided by Prof. S. Karpov (St-Petersburg State University). The latter strain was originally identified in TEM sections as co-inhabitant of this culture, and later recovered using light microscopy. The newly isolated strains were cloned twice, and subsequent studies were performed only on clones. Cultures were maintained in liquid Prescott and James (PJ; Prescott and James 1955) medium with addition of Cerophyl as a source of nutrients $(0.025 \% \mathrm{w} / \mathrm{v})$. For detailed light microscopic investigations amoebae were allowed to attach to glass coverslips in a drop of medium and observed on temporary slides sealed with Vaseline to prevent drying. Either Carl Zeiss Axiovert 200 or Leica DM2500 light microscopes were used for observations, both with differential interference contrast (DIC) and 100 $\times$ oil immersion lenses. Direct observations in cultures, including studies of the floating forms, were additionally performed using a Leica DMI3000 inverted microscope with phase contrast and integration-modulation contrast (IMC). Transmission electron microscopic (TEM) studies were performed on Negev 3-2c and SK1 strains. Amoebae were fixed directly in Petri dishes using the same protocol as described previously (Kudryavtsev 2014) and embedded in Embed 812 (EMS) epoxy resin after dehydration in a graded ethanol series followed by $100 \%$ acetone. Ultrathin sections were cut using Leica UC7 ultramicrotome and after a standard double-staining observed using a JEOL Jem1400 electron microscope operated at $80 \mathrm{kV}$.

\section{Molecular phylogenetic study}

Total DNA was purified from the cultures using guanidine isothiocyanate method (Maniatis et al. 1982). Complete sequences of the small-subunit (SSU) rRNA gene and sequences of the barcoding region of COI gene were obtained as described previously (Kudryavtsev and Pawlowski 2015). To evaluate the degree of variability between different molecular clones in the SSU rRNA gene, amplicons were cloned, and complete sequences of multiple clones were obtained. In order to exclude Taq-polymerase influence on the detected variability through PCR recombination, three amplification approaches where applied: (1) amplification using standard optimal conditions; (2) amplification with annealing temperature increased to the maximal value, at which the product could still be obtained (identified by gradient PCR); (3) amplification with maximal annealing temperature and maximal dilution of genomic DNA template (1000-10000×). Amplification products were purified using DNA Cleanup PCR Purification Kit (Evrogen), ligated into pTZ57R/T vector (Fermentas) and cloned in competent E.coli cells strain JM107. Not less than 40 molecular clones for each strain were sequenced on an ABI Prism 3500xl automated sequencer.

Multiple sequences of Ripella spp. obtained during this study were automatically aligned with each other using MUSCLE algorithm (Edgar 2004) in Seaview v. 4.6.2 (Gouy et al. 2010). Afterwards, they were manually aligned with our database of $>500$ sequences of various Amoebozoa and opisthokonts and unambiguously identified based on this alignment as belonging to Ripella spp. due to specific deletions typical of this genus. To determine the location of the sites where intragenomic variation of the SSU rRNA gene occurred, the secondary structure of the SSU rRNA molecule was reconstructed based on the models proposed by Wuyts et al. $(2000,2001)$ taking into account the alignment of the sequence with previously reconstructed SSU rRNA models of Amoebozoa (Kudryavtsev 2014; Kudryavtsev et al. 2009, 2011, 2014; Sims et al. 1999). Structure of some of the helices was reconstructed using mfold server (Zuker 2003). The final model was drawn using Adobe Illustrator. To reconstruct the phylogenetic relationships of Ripella spp. with the other Vannellidae based on the SSU rRNA gene sequences an alignment was constructed consisting of 90 sequences comprising members of the order Vannellida (80 sequences) and Dactylopodida (10 sequences) used as an outgroup with 1404 unambiguously aligned nucleotide sites. In an attempt to get a better resolved tree showing the relationships within the genus Ripella an alignment consisting of only available sequences of Ripella spp. (24 sequences) and 1520 nucleotide sites was constructed to build the unrooted tree. For phylogenetic analysis based on the COI gene an alignment consisting of the 14 obtained sequences and 37 published sequences of the other Amoebozoa with 663 nucleotide sites was constructed. Phylogenetic trees were reconstructed using maximum likelihood (ML) 
Table 1. Frequency (in percentage) of various locomotive form shapes in the studied species. Shapes of the locomotive form are designated according to Fig. 1.

\begin{tabular}{|c|c|c|c|c|c|c|}
\hline \multirow[t]{2}{*}{ Species } & \multicolumn{6}{|c|}{ Locomotive form shapes } \\
\hline & A & $\mathrm{B}$ & $\mathrm{C}$ & $\mathrm{D}$ & $\mathrm{E}$ & $\mathrm{F}$ \\
\hline Ripella tribonemae $\mathrm{n} . \mathrm{sp} .(\mathrm{n}=72)$ & 51.4 & 20.8 & 18.1 & 1.4 & 4.2 & 4.2 \\
\hline Ripella decalvata $\mathrm{n} . \mathrm{sp} .(\mathrm{n}=131)$ & 54.2 & 14.5 & 23.7 & 2.3 & 0 & 5.3 \\
\hline
\end{tabular}

algorithm implemented in RaxML v. 8.2.9 (Stamatakis 2014) and PhyML v. 3.0 (Guindon et al. 2010). Bayesian analysis was done using MrBayes v. 3.2.6 (Ronquist et al. 2012). General time-reversible model with gamma distribution of intersite rate variation and proportion of invariable sites was used (25 rate categories in RaxML, 4 in PhyML and 8 in MrBayes). ML analysis used 100 random starting trees in RaxML and 10 in PhyML, the best tree was bootstrapped with 1000 pseudoreplicates. Bayesian analysis used 2 runs of 4 simultaneous MCMC chains with 10000000 generations for the SSU rRNA gene dataset and 40000000 generations for the COI dataset and a burn in of $25 \%$ in each case. Average standard deviations of the split frequencies in the end of the runs were 0.003 . The numbers of generations and proportions of samples discarded as the burn in were determined based on the run results analysis using Tracer v. 1.6 (Rambaut et al. 2014). New sequences obtained during this study are deposited in Genbank with accession numbers: MF683472-MF683516 (Ripella platypodia SSU rRNA gene), MF683609-MF683614 (R. platypodia COI), MF683517-MF683566 (R. decalvata SSU rRNA gene), MF683615- MF683621 (R. decalvata COI), MF683567MF683608 (R. tribonemae SSU rRNA gene), MF683622 ( $R$. tribonemae $\mathrm{COI})$.

\section{Results}

\section{Light microscopic morphology of the living amoebae}

Both species demonstrated very similar morphology when studied with the light microscope, we therefore provide a common description paying special attention to the differences in details between the two strains. During locomotion amoebae adopted a fan-shaped morphotype (Smirnov and Brown 2004), and were rounded, fan-shaped or elongated triangular in above view. The anterior margin of the locomotive forms was always arc-shaped, while the lateral and posterior margins could be convex or straight. Overall diversity of the locomotive forms could be schematically represented by 6 variants summarized in Fig. 1 with unequal frequency of occurrence (Table 1). The most typical locomotive forms (51.4\% in $R$. tribonemae n. sp. and $54.2 \%$ in $R$. decalvata $\mathrm{n} \mathrm{sp}$.) were rounded or fan-shaped, with rounded lateral and

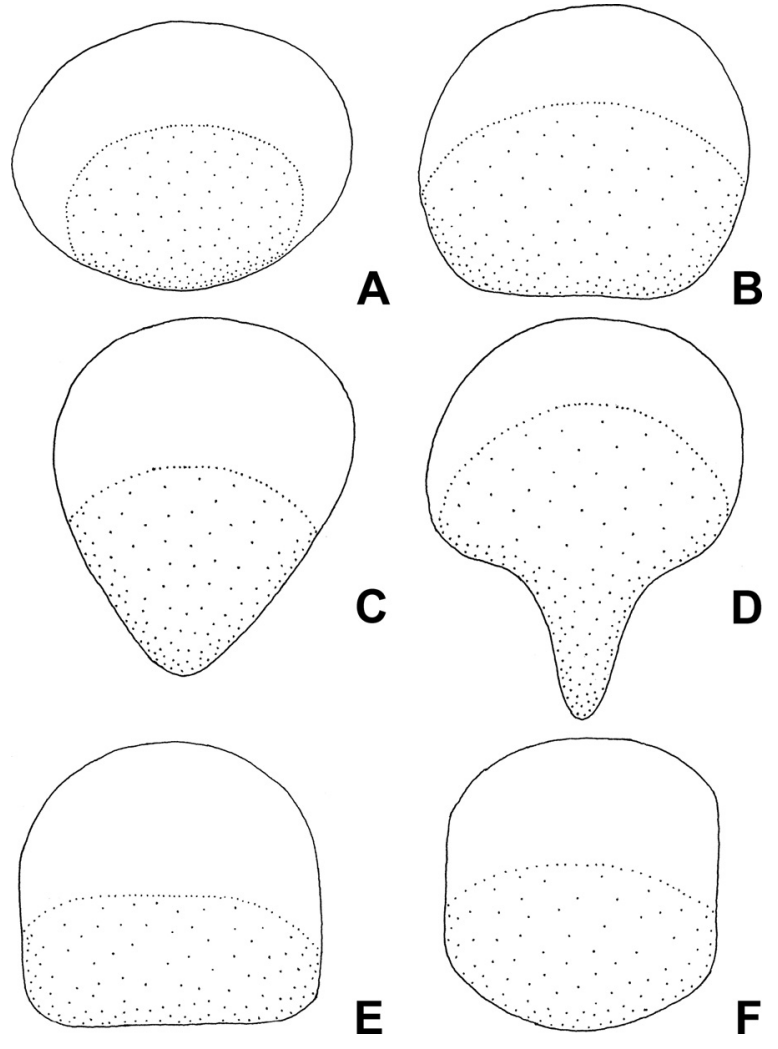

Fig. 1. Generalized scheme showing main features of the contours of locomotive forms in the described species of Ripella. A. Archshaped posterior and lateral margins. B. Arch-shaped lateral margins and straight posterior margin. C. Wedge-like shape caused by the posterior extension of the cell. D. "Fan with a handle" shape resulting from adhesion and extension of the posterior end of the cell. E. Straight posterior and lateral margins. F. Straight lateral and archshaped posterior margins.

posterior margins (Figs. 2, 12 ). About 1/5 of the cells in both species had a straight posterior margin, perpendicular to the direction of movement, while another $1 / 5$ of the cells had elongated triangular shape with tapering posterior end (Figs. $2,13,14)$. The least frequently adopted shapes were those of a "fan with a handle" forming a tapering, elongated uroidal projection (Figs. 3, 16), and those with straight lateral edges, parallel to the direction of movement (Fig. 15). Amoebae typically adopted the former shape when their posterior margin temporarily adhered to some object, usually a bacterial floc or the substratum, when locomotion was observed in the Petri 

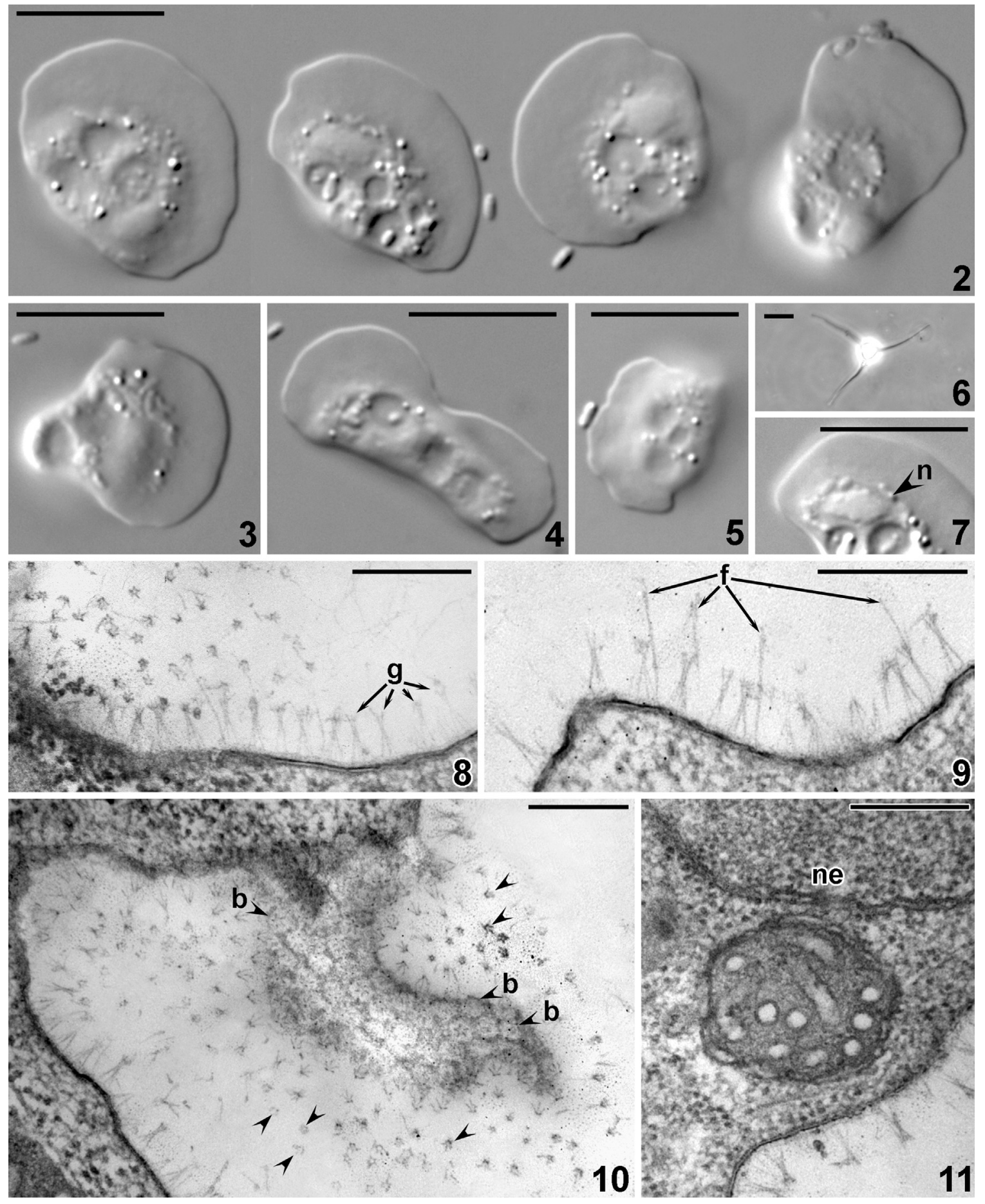

Figs. 2-11. Ripella tribonemae n. sp. Light (2-7) and electron (8-11) micrographs. 2. Most frequent shapes of the locomotive forms on the glass surface (DIC). 3. One of the rare shapes adopted during locomotion (DIC). 4. Amoeba changing the direction of movement with the frontal hyaline area divided into two parts moving in the opposite directions (DIC). 5. Amoeba during non-directional movement (DIC). 6. Floating form in culture (phase contrast). 7. Nucleus in the living amoeba (n; DIC). 8-9. Vertical sections of the cell coat showing glycostyles (g) and simple filaments (f) making up parts of the glycocalyx. 10. Tangential section of the cell surface showing bases of the glycostyles (b) and glycostyle cross-sections at different levels (arrowheads). 11. Section of a mitochondrion near nuclear envelope (ne). Scale bar $=10 \mu \mathrm{m}$ in $\mathbf{2 - 7}, 0.25 \mu \mathrm{m}$ in $\mathbf{8}-\mathbf{1 1}$. 

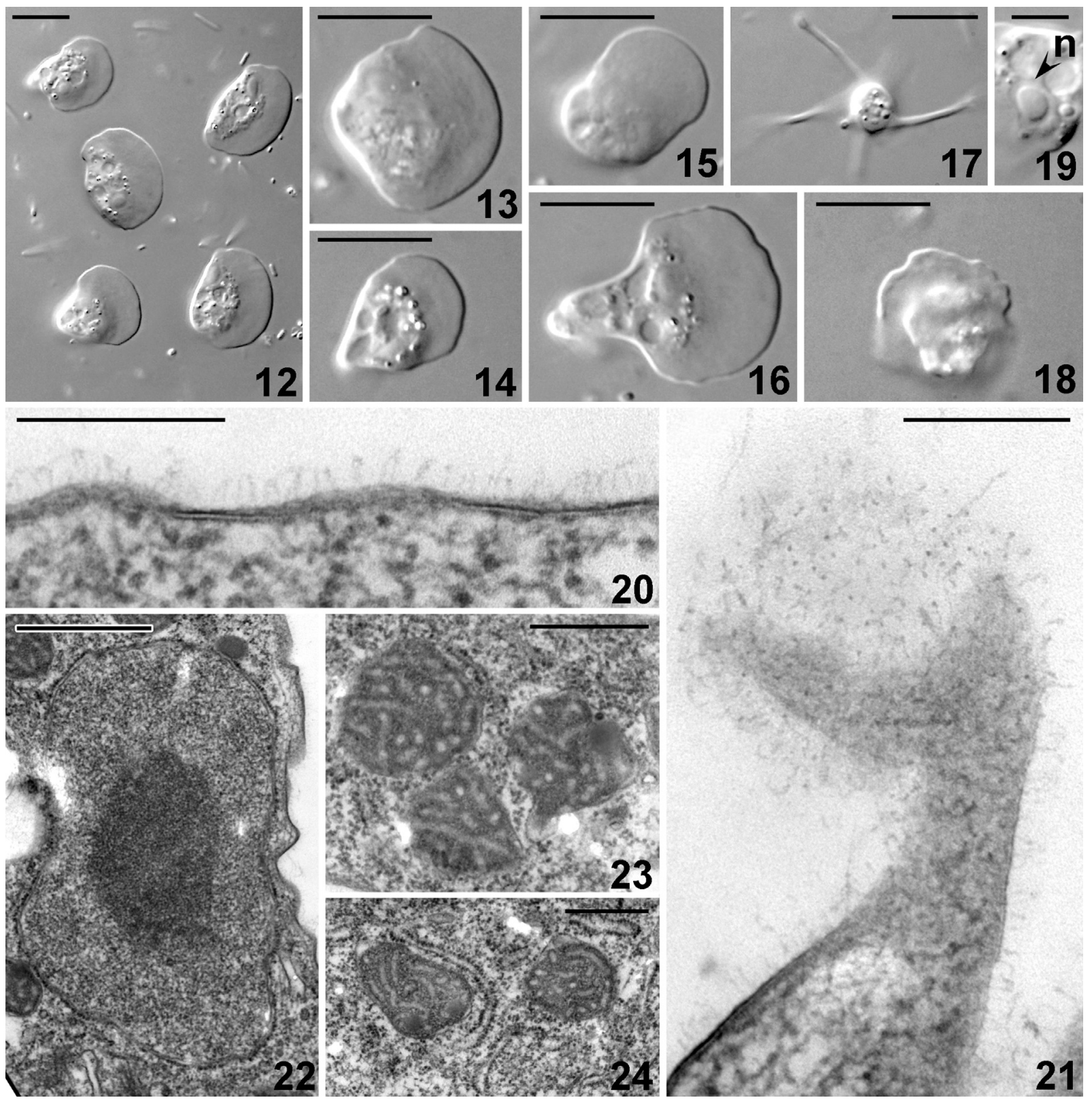

Figs. 12-24. Ripella decalvata n. sp. Light (12-19) and electron (20-24) micrographs. 12-14. Shapes of the most frequently occurring locomotive forms on glass surface (DIC). 15-16. Less frequently adopted locomotive forms (DIC). 17. Floating form (DIC). 18. Amoeba during non-directional movement on the glass surface (DIC). 19. Nucleus (n, DIC). 20. Part of the vertical section of the cell coat. 21. Cell coat in tangential section. 22. Nucleus. 23. Mitochondria. 24. Mitochondria in association with rough endoplasmic reticulum in the cytoplasm. Scale bar $=10 \mu \mathrm{m}$ in $\mathbf{1 2 - 1 8}, 5 \mu \mathrm{m}$ in $\mathbf{1 9}, 0.25 \mu \mathrm{m}$ in $\mathbf{2 0 - 2 1 ,} 1 \mu \mathrm{m}$ in $\mathbf{2 2}, 0.5 \mu \mathrm{m}$ in $\mathbf{2 3 - 2 4}$.

dish. The prominent frontal hyaline area usually surrounded posterior mass of granuloplasm from anterior and lateral sides and occupied 1/3-1/2 of the cell. There were no subpseudopodia, but the anterior margin of the cell could be somewhat wavy in $R$. tribonemae (Fig. 2). Uroid was smooth. Change of direction during locomotion occurred frequently, by the lateral expansion of the hyaline area towards the new direction of movement. Sometimes during this process the frontal hyaline area became temporarily split into two parts expanding in two different directions (Fig. 4). Rate of locomotion at room temperature $\left(+18-22^{\circ} \mathrm{C}\right.$ ) was $21-38 \mu \mathrm{m} / \mathrm{min}$ (average $29 \mu \mathrm{m} / \mathrm{min} ; \mathrm{n}=22$ ) in $R$. decalvata $\mathrm{n}$. sp. and $13-28 \mu \mathrm{m} / \mathrm{min}$ (average $19 \mu \mathrm{m} / \mathrm{min} ; \mathrm{n}=5$ ) in $R$. tribonemae $\mathrm{n}$. sp.

Non-directionally moving and stationary amoebae had an irregular shape (Figs. 5, 18), usually rounded or elongated. Their peripheral hyaline area was narrower than in the loco- 
motive forms and had an uneven margin. Floating forms were radial, their cytoplasm consisted of a spherical central mass of granuloplasm and 3-7 radiating hyaline pseudopodia that were straight or slightly curved (Figs. 6, 17). Length of the pseudopodia was 2-3 times the diameter of the central granuloplasmic mass. Spontaneous formation of the floating forms was very rarely observed either in culture (Fig. 6) or on slides (Fig. 17). For observation, their formation had to be induced by agitation of the culture. Amoebae had a single nucleus that was conspicuous, and usually was located in the anterior part of the granuloplasm, near the border between posterior granuloplasm and the anterior hyaline area. The nucleus had an oval shape with the large nucleolus occupying significant part of the nuclear volume (Figs. 7, 19). The nucleolus in $R$. tribonemae had often somewhat uneven, lobate surface (Fig. 7), while the surface of a nucleolus in $R$. decalvata was usually smooth (Fig. 19). Granuloplasm of both species contained a single contractile vacuole usually located close to the posterior cell margin, a number of digestive vacuoles with engulfed bacteria, and a number of granules, among which some had a spherical shape and diameter below $1 \mu \mathrm{m}$, while others were elongated and were 1-1.5 $\mu \mathrm{m}$ in size. Encystment was never observed in our cultures. Amoebae fed on bacteria, the phagocytosis occurred either on the ventral side of the cell, when amoeba crawled over the food object (Fig. 2), or in the lateral parts of the hyaline margin, where the small trophic projections could extend towards the food objects as the cell was moving past them.

\section{Electron microscopy}

\section{Ripella tribonemae SK1 n. sp.}

The cell coat of this species consisted of a typical plasma membrane covered with the fuzzy basal layer of medium electron density, which was 9.02-17.15 nm thick (average $13.04 \mathrm{~nm} ; \mathrm{n}=18$ ). Pentagonal tower-like glycostyles were emerging from this layer (Figs. 8-10). Measured length of the glycostyles was 58.43-108.92 nm (average $87.34 \mathrm{~nm} ; \mathrm{n}=69$ ). Filaments $138.75-208.92 \mathrm{~nm}$ long (average $171.58 \mathrm{~nm} ; \mathrm{n}=20$ ) were seen between the glycostyles in favorable sections (Fig. 9). Tangential sections of the cell coat showed glycostyles cut at different levels typically demonstrating star-like pentagonal structure (Fig. 10). Distance between neighboring glycostyles measured in sections was 30.71-89.84 nm (average $54.5 \mathrm{~nm}$; $\mathrm{n}=36$ ). Diameters of the glycostyle bases measured in tangential sections was 46.89-62.18 nm (average 57.1 nm; n=11). Mitochondria (Fig. 11) had branching tubular cristae, and the nucleus in sections was irregularly ovoid, with inconspicuous central nucleolus. The nuclear envelope did not carry any additional structures (Fig. 11).

\section{$R$. decalvata n. sp. Negev 3-2c}

The cell coat consisted of the plasma membrane covered with a loose layer of bent filaments (Fig. 20), which did not demonstrate any complex structure in the tangential sections (Fig. 21). Thickness of this layer measured in the sections was 39.52-63.16 nm (average $49.91 \mathrm{~nm} ; \mathrm{n}=26$ ), while distance between neighboring filaments was 17.06-39 nm (average $27.02 \mathrm{~nm} ; \mathrm{n}=28$ ). Nucleus in sections was irregularly ovoid, with the central nucleolus (Fig. 22). Mitochondria (Figs. 23-24) had branching tubular cristae, and were often located adjacent to the cisternae of rough endoplasmic reticulum (Fig. 24).

\section{Molecular phylogenetic relationships of the studied strains}

\section{Small-subunit (SSU) rRNA gene}

The SSU rRNA gene sequences of the two newly isolated strains and, in addition, the original strain of $R$. platypodia CCAP 1589/2 were unusually short as they lacked several considerable parts in the regions V2 and V4. Numbering of the SSU rRNA structural elements is given hereinafter according to Wuyts et al. (2000, 2001). Example of the SSU rRNA secondary structure reconstructed for $R$. platypodia is shown in Supplementary Fig. S1. Specifically, in the region $\mathrm{V} 2$ helices 8/e1-9 were significantly shorter than in other amoebozoans and helix 10/e1 completely absent. The hypervariable helices 23/e1-23/e7 of the region V4 were completely missing. The hypervariable region V7 (helix 43) was significantly shorter that in many discoseans (e.g., Dactylopodida and many Longamoebia), but comparable in length to the rest of the Vannellida. Phylogenetic analysis of the sequences resulted in a robust placement of the studied strains in a long clade of Ripella spp. branching deeply within Vannellida (Fig. 25). Taxonomic composition of this clade did not depend on either taxonomic sampling of the tree, or the set of alignment positions used. Besides the strains studied here, the clade comprised sequences of $R$. platypodia CCAP $1589 / 2$ and Ripella cf. platypodia from CCAP 1555/2 obtained by Smirnov et al. (2007). Unnamed strains Ripella spp. SUM1S/I, CAZ6/I, CAZ7/I, W181G/I, GERL14, GERL34, 805, DP13, GP2 and PS2, as well as an unnamed strain BEN3V originally designated Vannella sp. (Dyková and Kostka 2013; Dyková et al. 2005, 2010) also belonged to this clade. The clade of Ripella spp. was always robustly supported, however, its internal nodes and topology were moderately to poorly resolved and differed from what we expected based on identities of the previously obtained sequences and morphological comparison. In particular, a robustly supported clade was formed by Ripella spp. strains CAZ6 and W181G, which was sister to a clade formed by the rest of Ripella spp. $R$. tribonemae n. sp. was sister to GERL14 strain with moderate support (0.87/79), while $R$. decalvata $\mathrm{n}$. sp. was sister to a clade comprising $R$. platypodia and several unnamed strains. This position was supported only in Bayesian tree (BPP $=0.91)$. Branching of the newly obtained sequences of $R$. platypodia CCAP $1589 / 2$ was the most unusual, as they did not form a clade with the pre- 


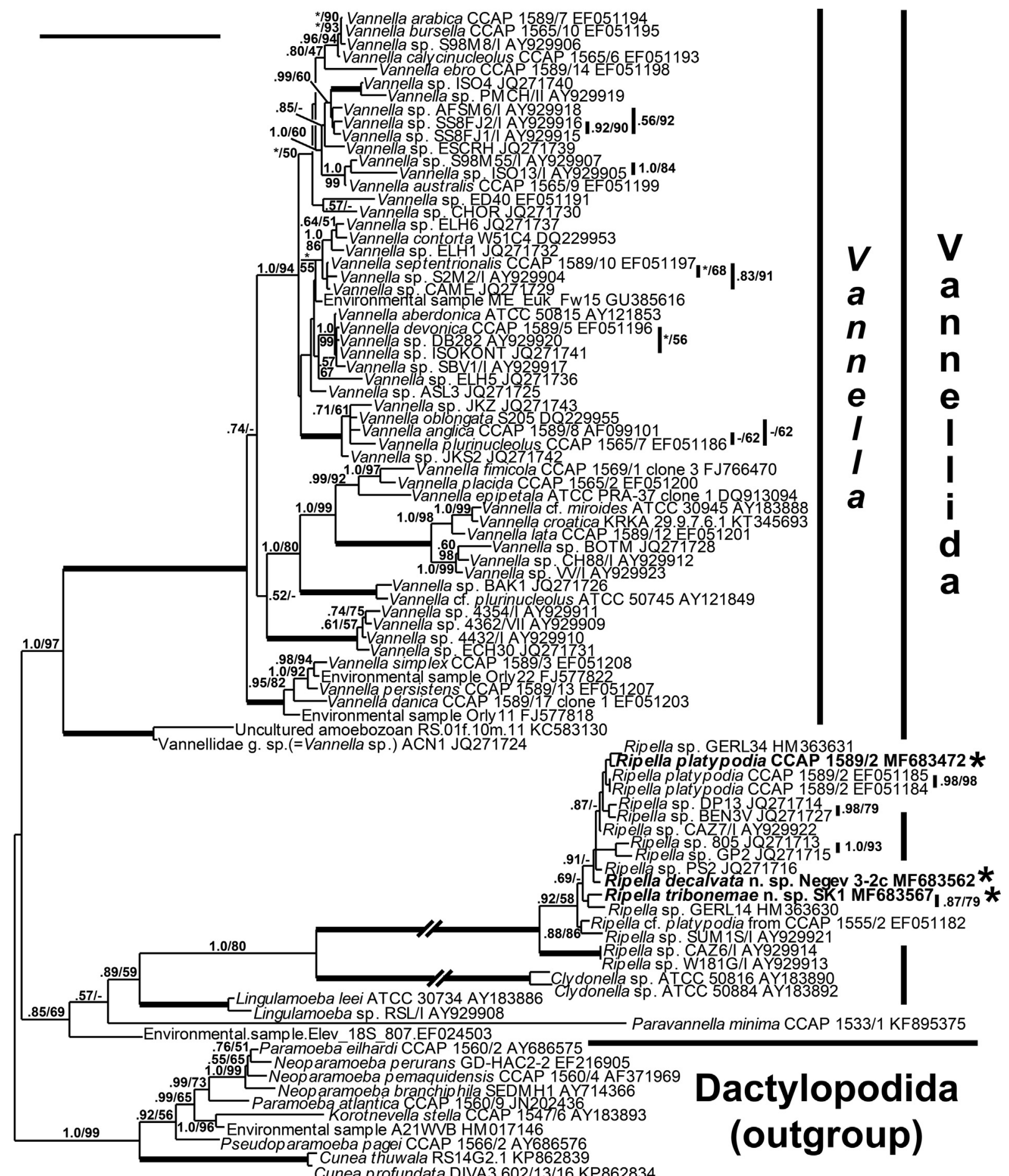

Fig. 25. Maximum likelihood phylogenetic tree based on 80 SSU rRNA gene sequences of Vannellida (ingroup) and 10 SSU rRNA gene sequences of Dactylopodida (outgroup) with 1404 unambiguously aligned nucleotide sites ( $\mathrm{LnL}=-14778.097984$ ). New sequences are in bold and marked with asterisks. Numbers at nodes indicate Bayesian posterior probability/bootstrap support values if above $0.5 / 50$. Thick branches correspond to 1.0/100 support. Length of the Ripella spp. and Clydonella spp. branches reduced twice. Scale bar $=0.1$ substitutions/site. 


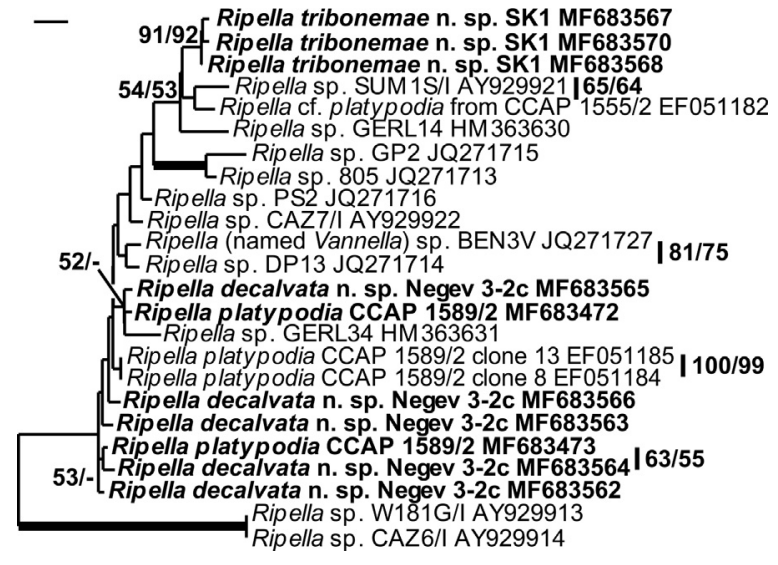

Fig. 26. Unrooted maximum likelihood tree of Ripella spp. based on SSU rRNA gene including all published full-length sequences and all full-length molecular clones initially sequenced during this study (24 sequences in total, 1520 unambiguously aligned nucleotide sites), $\mathrm{LnL}=-4742.670104$. New sequences are in bold. Numbers at nodes indicate bootstrap values for the trees obtained using RaxML/PhyML if above 50\%. Thick branches correspond to 100/100 support. Scale bar $=0.05$ substitutions/site.

viously obtained sequences of $R$. platypodia CCAP $1589 / 2$ (Smirnov et al. 2007), branching instead as a sister to Ripella sp. GERL34, but without support (Fig. 25).

The poorly resolved relationships within a clade of Ripella spp. might be caused by a low number of nucleotide positions available for analysis with the taxonomic set of all vannellids and several dactylopodids included in the tree (1404 nucleotide positions were chosen). As the sequences of Ripella spp. are short and strongly divergent compared to the other members of Vannellida, some of their nucleotide positions cannot be reliably aligned with those of the other genera, and some are completely missing. Therefore, an attempt to resolve the relationships in Ripella spp. was undertaken by analyzing the alignment consisting of only Ripella spp. (without outgroups) including as many positions as possible (Fig. 26). In this case sequences of all initially obtained molecular clones for all three strains were included. Due to extremely high variability of the sequences in certain sites (see below), only 1520 nucleotide positions could be used. The tree obtained was not significantly better resolved than the previous one, but differed in the position of the newly obtained sequences and provided several insights into their relationships with other strains of Ripella. In particular, all molecular clones of $R$. tribonemae $\mathrm{n}$. sp. formed a single clade that was sister to a clade comprising Ripella sp. SUM1S and Ripella cf. platypodia from the strain CCAP1555/2. A clade of these 3 strains was sister to Ripella sp. GERL14. Branching pattern of $R$. decalvata and the new sequences of $R$. platypodia was most interesting, as different molecular clones of $R$. decalvata did not form a single clade branching instead as a polyphyletic assemblage together with the previous and newly obtained sequences of $R$. platypodia CCAP $1589 / 2$ and Ripella sp. GERL34. Interestingly, two molecular clones of $R$. platypodia CCAP 1589/2 sequenced during this study never formed a clade with the previously obtained sequences of this strain branching separately with different molecular clones of $R$. decalvata n. sp. (Fig. 26).

\section{Cytochrome oxidase subunit I (COI) gene}

Lengths of the sequenced COI molecular clones of all Ripella spp. were 666 base pairs excluding PCR primers with the exception of one clone of $R$. decalvata carrying a deletion of one thymine residue in a position 619 . Sequenced molecular clones of $R$. platypodia CCAP $1589 / 2$ and $R$. decalvata $\mathrm{n}$. sp. (7 clones for each species) have shown some level of variability within PCR-products that was $0-0.4 \%$ in both species (average 0.13 and $0.11 \%$ respectively). Variability between these species was $0.4-0.7 \%$ (average $0.47 \%$ ), while that between each of these species and $R$. tribonemae was 5-5.2\% (average 5.07 and 5.06\%, respectively). In terms of the nucleotide substitutions this corresponded to 38 variable positions for all three species (Supplementary Fig. S2), but only two single-nucleotide substitutions occurred in all clones of $R$. platypodia and $R$. decalvata (positions 192 and 324). Most of these substitutions were synonymous, as only 4 variable sites were seen in the amino acid alignment (221 positions), and no amino acid substitutions that occur simultaneously in all molecular clones of a single species were observed. A phylogenetic tree based on the COI gene nucleotide sequences (663 alignment positions) showed a robustly monophyletic clade of Ripella spp. branching as sister to Vannella spp., while Paravannella minima Kudryavtsev, 2014 was the most basal vannellid, regardless of the algorithm of analysis. All molecular clones of R. platypodia CCAP $1589 / 2$ always formed a clade that was robustly sister to a clade of $R$. decalvata $\mathrm{n}$. sp., and $R$. tribonemae $\mathrm{n}$. sp. occupied a basal position (Fig. 27). Phylogenetic analysis of amino acid sequences yielded a similar tree topology, but $R$. platypodia and $R$. decalvata were completely mixed in this case.

\section{Intragenomic variability of the SSU rRNA gene in Ripella}

Comparison of the sequences from the initially obtained molecular clones of Ripella spp. SSU rRNA gene demonstrated several regions of the gene where the sequences were strikingly different, even though they were obtained from the product of a single PCR. Extensive cloning of the full-length PCR products of the three species yielded 42 sequences for Ripella tribonemae n. sp. SK1, 45 for $R$. decalvata Negev3-2c and 43 for R. platypodia CCAP 1589/2. Lengths of these sequences were 1679-1711 bp (average $1697 \mathrm{bp}$ ), 1691-1710 bp (average 1703 bp) and 1692-1713 bp (average $1703 \mathrm{bp}$ ), respectively. Sequenced clones of the SSU rRNA gene demonstrated a significant level of intragenomic variability, as only few pairs of identical molecular clones were revealed within each PCR product. Application of more stringent PCR conditions, in particular, diluted genomic DNA and increased annealing temperature $\left(63^{\circ} \mathrm{C}\right.$ for $R$. tribone- 


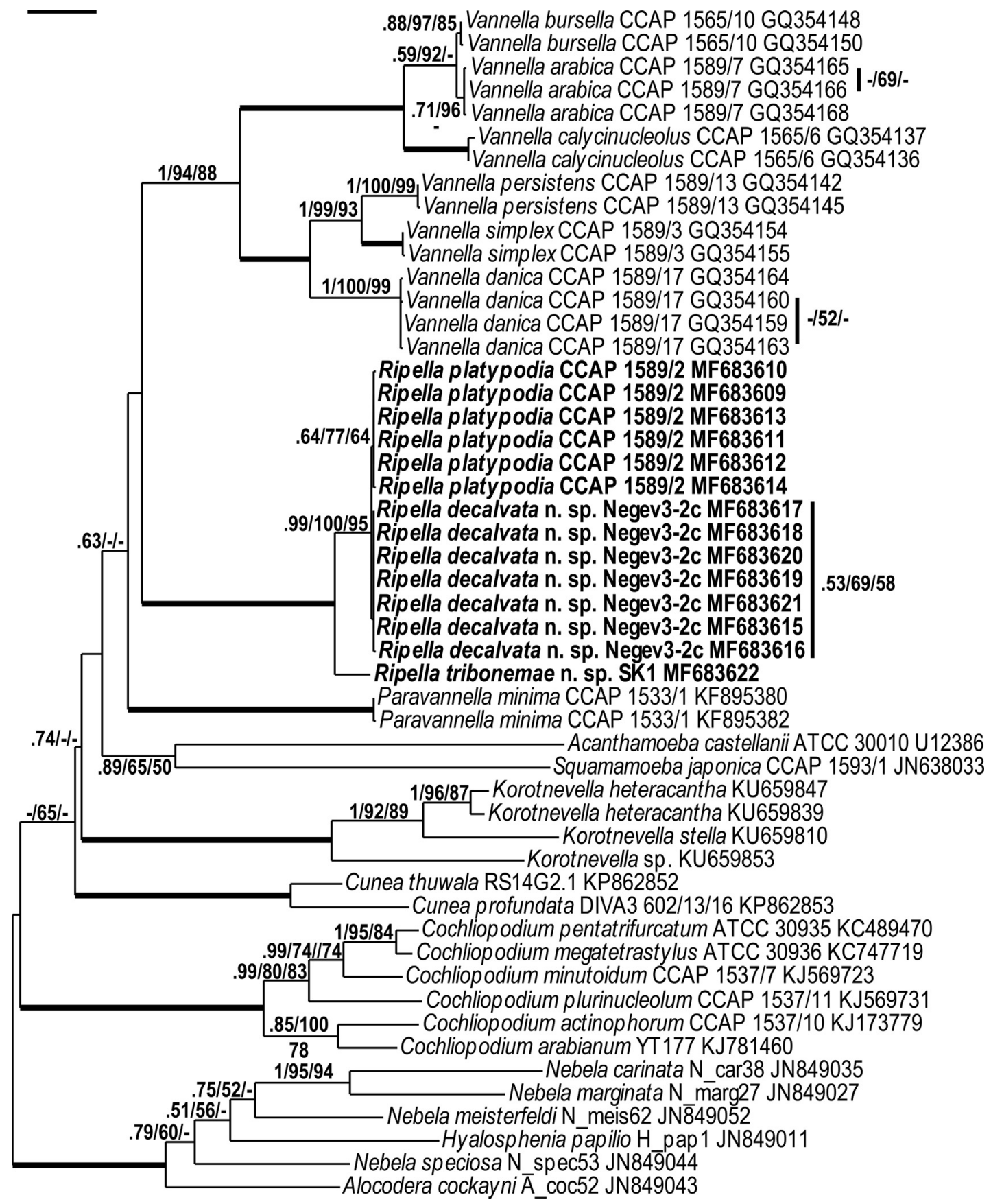

Fig. 27. Maximum likelihood phylogenetic tree of Amoebozoa based on the nucleotide sequences of the COI gene comprising 15 obtained sequences of Ripella spp. (in bold) and 36 published sequences from the other clades of Amoebozoa (663 nucleotide positions). The tree is rooted with Arcellinida. Numbers at nodes indicate Bayesian posterior probability/bootstrap support values for RaxML/bootstrap support values for PhyML if above 0.5/50/50. Thick branches correspond to 1.0/100/100 support. Scale bar =0.05 substitutions/site.

mae n. sp. and $R$. platypodia, and $61^{\circ} \mathrm{C}$ for $R$. decalvata n. sp.) did not reduce the number of sequence variants per reaction. Nucleotide differences between pairs of sequenced molecular clones within one strain were $0-10.5 \%$ (average $7.09 \%$ ) for $R$. decalvata $n$. sp., $0-15.9 \%$ (average $7.7 \%$ ) for $R$. tribonemae n. sp., and $0.3-11.7 \%$ (average $7.7 \%$ ) for $R$. platypodia CCAP $1589 / 2$. Differences in the short local variable regions were at the level of $0-74.6 \%$ (average
$54.1 \%$ ), 0-74.2\% (average 54.1\%) and 0.6-75.9\% (average $54.1 \%$ ), respectively. Differences between species comprised $4-12.5 \%$ of the nucleotides (average $8.6 \%$ ) for R. platypodia and $R$. decalvata, $9.1-19.5 \%$ (average $12.2 \%$ ) for $R$. platypodia and $R$. tribonemae and 8.6-19.8\% (average 12.3\%) for $R$. decalvata and $R$. tribonemae. Differences between species in the short local variable regions were $26.2-78.9 \%$ (average 
$56.6 \%$ ), $53.5-80.7 \%$ (average $70.3 \%$ ) and $51-82.2 \%$ (average $71.7 \%$ ), respectively.

Analysis of the aligned sequences of revealed 9 areas shared between all 3 species (Supplementary Table S1) demonstrating intragenomic variability located in 8 hypervariable regions of the SSU rRNA gene and in helix 13, which is not assigned to any hypervariable region according to the secondary structure model of SSU rRNA (Wuyts et al. 2000, 2001). In addition, two 3-nucleotide motifs showing 2 regular substitution patterns each were observed in helices $6 / \mathrm{e} 1$ and 23 in $R$. tribonemae n. sp. Areas where intragenomic variability occurred had variable length, and within these regions traces of all types of mutations, in particular, nucleotide substitutions, indels and duplications were observed. The number of different nucleotide patterns in each local region was finite, however, additional variability of the full sequences occurred by combining sites containing different nucleotide patterns within a single clone of SSU rRNA gene. Typically, dominating motifs were revealed in each of the variable regions, while other motifs were present in lower numbers (Supplementary Table S1). The maximal number of patterns inside the variable region was 25 . Lower variability of the sequence motifs was detected in the helix 13 and region V9 (3-4 motifs detected), while regions V2-V5, V7 and V8 showed broader range of patterns.

Mapping of these intragenomic variability areas onto the secondary structure model of $R$. platypodia SSU rRNA shows that most of these areas are restricted to the terminal parts of the relatively variable helices (Supplementary Fig. S1). Therefore, presence of different nucleotide patterns most likely did not influence the structural function of the molecule, with the exception of the variability in a usually relatively conserved pseudoknot area in the region V4 (helices 23/e11-23/e14).

\section{Discussion}

\section{Identification of the studied species}

An assignment of the new strains to the genus Ripella is fairly easy, as they all form a single, robust clade in the molecular phylogenetic tree of Amoebozoa based on the SSU rRNA gene. This clade includes also previously sequenced $R$. platypodia and a number of unnamed strains previously studied and illustrated by Dyková et al. (1996, 2005, 2010), and Dyková and Kostka (2013). SSU rRNA gene of the studied amoebae shared features characteristic of the genus Ripella, in particular, it is one of the shortest among Amoebozoa, with extensive deletions in the regions V2 and V4. However, morphological identification and assignment to species are rather difficult in this genus, and can be reliably performed only based on combined, morphological, ultrastructural and molecular evidence. Based on light microscopy, the studied strains are difficult to distinguish from each other. The only reliable differences were in the length:breadth ratio of the locomotive forms that was $0.62-1.52$ (average 0.98) in $R$. decalvata and 0.61-1.38 (average 0.88) in $R$. tribonemae indicating that the former species could become more elongated during locomotion, rate of locomotion that was faster in $R$. decalvata and also the shape of the nucleolus that could have more uneven and lobate surface in $R$. tribonemae than in $R$. decalvata.

Differences in the cell coat structure revealed using TEM were more reliable, as $R$. tibonemae possessed typical pentagonal tower-shaped glycostyles and filaments. By contrast, $R$. decalvata has a fuzzy cell coat without glycostyles. The species could be more easily distinguished from each other based on the molecular characters as they branched separately in the phylogenetic trees and demonstrated a number of characteristic nucleotide substitutions in both, SSU rRNA and COI genes (Supplementary Fig. S2). However, $R$. decalvata shows very few molecular differences from $R$. platypodia, type strain CCAP 1589/2 studied by Page (1968) and Page and Blakey (1979). R. tribonemae branched as a separate, robustly supported clade in the molecular tree of Ripella spp. based on the SSU rRNA gene, which was sister to the unnamed strains SUM1S/I (Dyková et al. 2005) and Ripella cf. platypodia from CCAP strain 1555/2 (Smirnov et al. 2007). By contrast, different molecular clones of $R$. decalvata were scattered in the tree, and were mixed up with the molecular clones of $R$. platypodia CCAP 1589/2 sequenced during the present study. Moreover, two SSU rRNA gene sequences of the CCAP 1589/2 strain obtained previously (Smirnov et al. 2007) branched separately from the sequences of this strain that we obtained. These differences may only be due to the individual variation between molecular clones (see below), moreover, a detailed comparison between the SSU rRNA gene sequences of the strains previously studied by Dyková et al. (2005), and Dyková and Kostka (2013) shows that the only two strains well separated from other Ripella spp. are CAZ6 and W181G (Dyková et al. 2005), while the variability between others is restricted to the revealed local areas of the gene showing putative intragenomic variability, so that it can be considered either as inter-, or as intraspecific variability. Yet, $R$. decalvata demonstrates two stable single-nucleotide substitutions in the COI gene, compared to $R$. platypodia. In addition, it differs from the latter species in the absence of glycostyles and filaments in the cell coat (Page and Blakey 1979).

Differences in the cell coat structure may be interpreted in three different ways: (1) The cell coat structure is stable within the life cycle of the cell and strain, and should be considered as one of the characters useful for species identification. In this case, we may consider $R$. decalvata as a separate species from $R$. platypodia, as in addition to a different cell coat structure it differs from $R$. platypodia in SSU rRNA and COI genes. (2) The cell coat may change its structure within the life cycle of an individual cell or may vary between different clones of the same species. In this case, this character is not relevant for species identification in Ripella, and the only valid differences that remain are sta- 
ble differences in the molecular sequences that are present in all molecular clones. We may then easily consider all currently known Ripella strains except CAZ6, W181G and $R$. tribonemae as belonging to a single species $R$. platypodia. (3) The cell coat structure that we demonstrate in $R$. decalvata is an artifact due to the destruction of glycostyles during fixation and embedding. In this case, this strain has no differences from $R$. platypodia in the cell coat structure and may be assigned to this species. The latter option seems to be least probable, as these amoebae were fixed for TEM study simultaneously with $R$. tribonemae using the same protocol. This is hardly probable, that in all cells of the latter strain the glycostyles could be preserved, while in the former one destroyed by the same fixation procedure. Therefore, we need to select between the first 2 options, and in this case we prefer the former interpretation, i.e. that the differences in the cell coat structure may be considered as distinguishing species. This is the most simple and preferred explanation at the moment, as no data showing the opposite have ever been obtained. Therefore, we describe $R$. decalvata as a separate species. The results obtained suggest that it is necessary to evaluate the pattern of variability within Ripella in the cell coat structure, and understand how this pattern is related to the variability between different strains in the SSU rRNA gene sequences.

\section{Species diversity in Ripella}

Analysis of the published drawings and light micrographs of Ripella spp. (Dyková et al. 1996, 2005, 2010; Dyková and Kostka 2013; Page 1968; Page and Blakey 1979; Smirnov et al. 2007) shows that all currently known strains assigned to this genus are very similar to each other and to the type species $R$. platypodia in the set of light microscopic characters. Shapes and sizes of locomotive forms and structure of nucleus are nearly identical, while floating forms have only been illustrated for R. platypodia (Page 1968; Smirnov et al. 2007) and two species investigated during the present study. These amoebae are more diverse in the structure of their cell coat. Indeed, $R$. platypodia, $R$. tribonemae and strains CAZ6, DP13, GP2, PS2 and BEN3V studied by Dyková et al. (2005), Dyková and Kostka (2013) have a glycocalyx that includes typical pentagonal glycostyles and simple filaments. It is noteworthy that the latter of the mentioned strains is listed among Vannella by Dyková and Kostka (2013), but clearly belongs to Ripella based on our analysis, being most closely related to DP13 strain. By contrast, $R$. decalvata studied here, together with strains 805, CAZ7, GERL14, GERL34, SUM1S and W181G (Dyková et al. 2005; Dyková and Kostka2013) have a cell coat consisting of filamentous structures, usually $50-60 \mathrm{~nm}$ in length. This character can be more reliable for the morphological identification of species in Ripella, provided that it is stable within an isolate, however, the details of cell coat structure are poorly correlated with the molecular diversity of Ripella strains based on the SSU rRNA gene. Indeed, strains W181G and CAZ6 that form a separate clade in the phylogenetic tree (Fig. 26) have differ- ent cell coats. Strains 805 and GP2 are also closely related, while $R$. decalvata is most closely related to a type strain of $R$. platypodia. This is identical to the situation in the genus Vannella where pairs of species almost identical in the SSU rRNA gene sequences may also have contrasting cell coat structure (Smirnov et al. 2007) and requires a reevaluation of the composition of Ripella spp. based on ultrastructure and molecular data to clarify the status of the unnamed strains belonging to this genus. Our findings show that SSU rRNA gene is hardly suitable as a molecular marker for this purpose as it shows a significant variability within a genome in these amoebae (see below) and its variation among many of the strains is restricted only to these short variable regions. There are only two regions in the SSU rRNA gene restricted to the helices 6/e1 and 8/e1 (positions 76-104 and 156-166 in $R$. platypodia CCAP 1589/2 EF051184, respectively) where the nucleotide patterns are stable within clones, but differ between them. Therefore, we suggest that another marker has to be used for molecular distinction of species in Ripella, and the COI gene can be a good candidate for this purpose, as it was previously shown in the other clades of naked lobose amoebae (Geisen et al. 2014; Nassonova et al. 2010; Tekle 2014; Zlatogursky et al. 2016). Indeed, this marker yielded two stable single-nucleotide differences between $R$. platypodia and R. decalvata, which differ by their cell coat structure, while $R$. tribonemae differs from both of these species in 32 nucleotide positions (Supplementary Fig. S2), which is significantly higher than the level of differences in the above mentioned areas of the SSU rRNA gene. This shows that this marker deserves attention, but, unfortunately, it has not been sequenced in any of Ripella strains besides those studied here.

\section{Unusual pattern of SSU rRNA gene variability in Ripella}

Ribosomal RNA genes are typically organized in the eukaryotic genomes as tandem repeats comprising SSU rRNA gene, a cluster of internal transcribed spacers and 5.8S rRNA gene (ITS1-5.8S-ITS2), and LSU rRNA gene (reviewed in e.g., Long and Dawid 1980). Multiple copies of this array are usually present in the genome, but in most organisms they show little to no intragenomic variability due to the process of concerted evolution, which homogenizes sequences of multiple-copy genes within a genome (e.g., Brown et al. 1972; Dover 1982; Elder and Turner 1995; Ganley and Kobayashi 2007; Liao 1999). However, exceptions showing intragenomic polymorphism in these genes were reported from both, unicellular and multicellular eukaryotes. The degree of this polymorphism is different. The studies performed on multicellular organisms were mostly focused on ITS loci (e.g., Campbell et al. 1997; Gandolfi et al. 2001; Hugall et al. 1999) with recorded intragenomic divergence of up to $26 \%$. Fewer studies demonstrate intragenomic sequence polymorphism in the rRNA genes, but, for example, this polymorphism was recorded in 4 species of fungi (Simon and Weiss 2008), and was shown to be repre- 
sented mainly by single-nucleotide polymorphisms (SNPs) evenly distributed along the analyzed parts of the markers.

The intragenomic variability of ribosomal cluster was also demonstrated in various groups of protists, for example, ciliates (Gong et al. 2013), foraminifera (Pillet et al. 2012) and dinoflagellates (Gribble and Anderson 2007; Miranda et al. 2012). In Amoebozoa some SSU rRNA gene sequence variation between different molecular clones of the same amplicon does occur, and is usually detected by sequencing multiple clones of the PCR product amplified from the genomic DNA. Smirnov et al. (2007) mentioned this for the first time in the SSU rRNA genes of Vannellidae and suggested this could be due to the intragenomic variation. Further, Nassonova et al. (2010) demonstrated sequence divergence at the level of up to $3.2 \%$ in the SSU rRNA gene and up to $7.5 \%$ in the ITS1-5.8S-ITS2 locus in Vannella spp. Similar variability in the SSU rRNA gene was shown in Himatismenida (Geisen et al. 2014; Kudryavtsev et al. 2011), Arcellinida (Kudryavtsev et al. 2009), Pellitida (Kudryavtsev et al. 2014), some of the Archamoebae (Ptáčková et al. 2013) and some of the Dactylopodida (Kudryavtsev and Pawlowski 2015; Zlatogursky et al. 2016). In most of the above-cited papers the detected variability of the ribosomal genes within the genome appears to be random. At the same time, in Korotnevella spp. (Zlatogursky et al. 2016) and some of the archamoebids (in particular, Mastigamoeba abducta and Rhizomastix libera; Ptáčková et al. 2013) the pattern of variability seems to be similar to our findings in Ripella. For example, in the studied species of Korotnevella the SSU rRNA gene variability within a clonal strain reached $9.4 \%$, and besides random substitutions several repeated nucleotide motifs were detected in the helices 43 and 45/e1 (regions V7 and V8).

While the pattern of variability detected in the strains studied here is similar to these previous reports, the level of this variability appears to be the highest among Amoebozoa to our knowledge. The highest level of intragenomic differences between different molecular clones of the SSU rRNA gene in Ripella reaches $15.9 \%$, which is comparable to differences between species, and this variation is mostly due to the presence of repetitive nucleotide patterns in restricted areas of the marker (Supplementary Fig. S1, Supplementary Table 1). Identical location of these areas in 3 independently isolated strains suggests that this pattern of intragenomic SSU rRNA gene variation is a characteristic feature of the whole genus Ripella. This result poses further questions concerning the nature of this variability in Ripella. In particular, the results reported here suggest a violation of the concerted evolution process in Ripella, at least, to some extent. This is usually considered to be correlated with the number of copies of the ribosomal cluster in the genome and the presence of extrachromosomal copies of this locus, which is common in various unicellular eukaryotes (Gong et al. 2013; Long and Dawid 1980). This suggests an unusual organization and high copy number of the ribosomal cluster in the genome of Ripella. The second question stems from the fact that our findings are based on the sequencing of amplicons obtained using the genomic DNA. Therefore, we cannot distinguish between transcribed and non-transcribed sequence variants. It was previously shown that, for example, in dinoflagellates about half of the variable LSU rRNA gene copies are pseudogenes, which are not expressed (Gribble and Anderson 2007). The results reported here suggest that the observed variability seemingly does not violate the secondary structure of the SSU rRNA molecule, except probably in a site containing helices 23/e11-23/e14, so there is no evident reason for considering part of the sequences obtained to be non-expressed pseudogenes.

Anyway, the presented data show the uniqueness of the SSU rRNA gene in Ripella that causes consequences for the use of this marker as a DNA barcode and in metagenomic studies. In particular, the currently proposed 2-level concept of DNA barcoding in protists suggests the use of the hypervariable region V4 of SSU rRNA gene as the first-level "universal" barcode (Pawlowski et al. 2012). This is not possible in Ripella due to the absence of a hypervariable part of this region (made up of helices 23/e1-23/e7). With the considerable level of intragenomic variability, caution should be observed when the diversity of species in natural habitats is evaluated using SSU rRNA gene, as different sequence variants that can be attributed to different species may, in fact, originate from the same genome.

\section{In search of a morphological definition of Ripella}

Deeply-branching clades of Vannellida interpreted as different genera are usually difficult to define based on morphological characters (Kudryavtsev 2014). Due to the small size of the cell, morphological differences are elusive, and the diagnosis of the genus Ripella is essentially based on molecular data (Smirnov et al. 2007). However, a careful comparison of the genera based on the available data allows at least some suggestions as per how they can be distinguished morphologically. In particular, in spite of similarity in small size and cell coat structure, Ripella spp. differ clearly from Paravannella in having a predominantly arc-shaped posterior edge during locomotion (Fig. 1A), and frontal hyaline area broadly expanding laterally, so that change of direction during locomotion is often accompanied by formation of two parts of hyaloplasm moving in the opposite directions. Moreover, the drop-shaped locomotive forms with expanded posterior end (Fig. 1C) are regularly adopted by the cells in Ripella (ca. 1/5 of all observations), and almost never present in Paravannella (Kudryavtsev 2014). In addition, the floating form in Ripella has much longer and thinner radial pseudopodia than in Paravannella, while the nuclei in Ripella are larger, less elongated and have larger nucleoli than the predominantly ovoid to almost spindle-shaped nuclei of Paravannella.

Morphological differences between Ripella and Clydonella are less obvious and can only be deduced from the older light microscopic descriptions by Sawyer (1975a,b). Unfortunately, none of the strains currently studied using molecular techniques (ATCC 50816 and ATCC 50884; Peglar et al. 2003) represents an original isolate of 
Sawyer, and for none of them a full set of morphological characters was reported and illustrated. Therefore, we can only assume that these strains were assigned to the genus Clydonella correctly. Based on the Sawyer's (1975a,b) descriptions, the main differences between Ripella and Clydonella are the presence on numerous pronounced dorsal waves over the frontal hyaline area and shorter pseudopodia of the floating form with less sharply pointed tips in the latter genus. In addition, Clydonella seems to be much faster during locomotion than Ripella (usually around $40 \mu \mathrm{m} / \mathrm{min}$ ).

Members of the genus Lingulamoeba mainly differ from Ripella by having a lingulate shape with length in most cases exceeding breadth (Dyková and Kostka 2013; Sawyer 1975a) and no radiating pseudopodia in the floating forms (where observed). The outlined differences suggest that based on the morphological data currently being accumulated, there is a potential for morphological distinction of even the smallest and highly similar vannellid genera. However, implementation of these differences in the morphological diagnoses currently seems to be premature as too few members of each genus have been studied, and only some of them may be assigned to species originally described when the genera were established. Detailed microscopic studies of more species are needed, preferably combined with molecular evidence based on the same strains, to facilitate usage of these data in the morphological designation of the genera.

\section{Taxonomic appendix}

Amoebozoa: Discosea: Flabellinia: Vannellida: Vannellidae Bovee, 1970.

Genus Ripella Smirnov et al., 2007. Emended diagnosis: Fan-shaped, spatulate, or discoid amoebae, usually small and rapidly moving, without any ridges or waves on the dorsal surface and always with smooth outlines. 18S rRNA gene markedly shorter than in Vannella spp. and most other Amoebozoa due to deletions in the regions V2 causing shortening of helices 8/e1-10 and absence of helix 10/e1, and V4 causing absence of helices 23/e1-23/e7. Significant intragenomic variability in at least 9 local areas of the SSU rRNA gene. Characteristic signature between helices 8 and 10 (region V2) of the SSU rRNA (positions 138-207 in $R$. platypodia CCAP 1589/2, EF051184). ZooBank LSID: urn:lsid:zoobank.org:act:183A9D8A-2559-45E4-AED109E4B221806B; type species (by priority): $R$. platypodia (Gläser, 1912).

Ripella tribonemae n. sp. Diagnosis: length during locomotion $8.4-15.5 \mu \mathrm{m}$ (average $11.4 \mu \mathrm{m}$ ), breadth, $8.7-19.6 \mu \mathrm{m}$ (average $13.3 \mu \mathrm{m}$ ), length:breadth ratio, 0.61-1.38 (average 0.88) $(\mathrm{n}=98)$; diameter of nucleus $3.3-6.8 \mu \mathrm{m}$ (average $4.5 \mu \mathrm{m}$ ), of nucleolus, 2.3-5.1 $\mu \mathrm{m}$ (average $3.3 \mu \mathrm{m})(\mathrm{n}=54)$. Cell coat including pentagonal glycostyles ca. $90 \mathrm{~nm}$ long and filamentous structures ca. $170 \mathrm{~nm}$ long. ZooBank LSID: urn:1sid:zoobank.org:act:073898C3-07A5-4B78-B571-
EF35F873217F; observed habitat: contaminant of laboratory culture of Tribonema sp., type locality unknown; type material: type culture (CCMA0003), Epon embedding (F122) and total DNA sample (A521) are deposited with the Centre for Culture Collection of Microorganisms of St-Petersburg State University; etymology: tribonemae, derived from the genus name of the cultured alga where the amoeba species was initially found; molecular sequence data: Genbank accession number MF683567-MF683608 (SSU rRNA gene), MF683622 (COI).

Ripella decalvata $\mathrm{n}$. sp. Diagnosis: length during locomotion 8.3-20.4 $\mu \mathrm{m}$ (average 13.2 $\mu \mathrm{m}$ ), breadth, 7.6-22.4 $\mu \mathrm{m}$ (average $13.8 \mu \mathrm{m}$ ), length:breadth ratio, $0.62-1.52$ (average $0.98)(\mathrm{n}=132)$; diameter of nucleus $3.2-5 \mu \mathrm{m}$ (average $4 \mu \mathrm{m})$, of nucleolus, 1.8-3.6 $\mu \mathrm{m}$ (average $2.8 \mu \mathrm{m})(\mathrm{n}=52)$. Cell coat consisting of loose filamentous structures ca. $50 \mathrm{~nm}$ in length, no pentagonal glycostyles. ZooBank LSID: urn:lsid:zoobank.org:act:DAFA8179-B4E6-414C86F2-BD80D12A88CE; type locality: bottom sediments in the freshwater pond in Ein Yorke'am (Negev desert, Israel; N30.938562 E35.04087); type material: type culture (CCMA0004), Epon embedding (F114) and total DNA sample (A367) are deposited with the Centre for Culture Collection of Microorganisms of St-Petersburg State University; etymology: decalvata, (L., "shaven") refers to the absence of glycostyles and filaments in the cell coat; molecular sequence data: Genbank accession number MF683517-MF683566 (SSU rRNA gene), MF683615-MF683621 (COI).

\section{Acknowledgments}

We are grateful to Prof. Sergei Karpov (Saint-Petersburg State University) for providing sample containing Ripella tribonemae and Prof. Jan Pawlowski (University of Geneva) for collecting the sample containing $R$. decalvata. $R$. platypodia CCAP $1589 / 2$ was kindly provided by Undine AchillesDay (Culture Collection of Algae and Protozoa, UK). This study utilized the equipment of the Core Facility Centres "Culture Collection of Microorganisms" and "Development of Molecular and Cell Technologies" of the St-Petersburg State University. We are grateful to Alexey Masharsky and Elizaveta Gorodilova for excellent technical assistance with sequencing. Financial support was provided by the grants 15-04-06239-a from Russian Foundation for Basic Research (isolation and study of $R$. tribonemae) and 1.50.125.2014 from St-Petersburg State University (study of intragenomic polymorphism in the SSU rRNA gene of Ripella).

\section{Appendix A. Supplementary data}

Supplementary data associated with this article can be found, in the online version, at http://dx.doi.org/10.1016/ j.ejop.2017.09.003. 


\section{References}

Bovee, E.C., 1965. An emendation of the ameba genus Flabellula and a description of Vannella gen. nov. Trans. Am. Microsc. Soc. 84, 217-227

Brown, D.D., Wensink, P.C., Jordan, E., 1972. A comparison of the ribosomal DNA's of Xenopus laevis and Xenopus mulleri: the evolution of tandem genes. J. Mol. Biol. 63, 57-73.

Campbell, C.S., Wojciechowski, M.F., Baldwin, B.G., Alice, L.A., Donoghues, M.J., 1997. Persistent nuclear ribosomal DNA sequence polymorphism in the Amelanchier agamic complex (Rosaceae). Mol. Biol. Evol. 14, 81-90.

Dover, G., 1982. Molecular drive: a cohesive mode of species evolution. Nature 299, 111-117.

Dyková, I., Boháčová, L., Fiala, I., Macháčková, B., Pecková, H., Dvořákova, H., 2005. Amoebae of the genera Vannella Bovee, 1965 and Platyamoeba Page, 1969 isolated from fish and their phylogeny inferred from SSU rRNA gene and ITS sequences. Eur. J. Protistol. 41, 219-230.

Dyková, I., Kostka, M., 2013. Illustrated Guide to Culture Collection of Free-Living Amoebae. Academia, Praha.

Dyková, I., Kostka, M., Wortberg, F., Nardy, E., Pecková, H., 2010. New data on aetiology of nodular gill disease in rainbow trout, Oncorhynchus mykiss. Folia Parasitol. 57, 157-163.

Dyková, I., Lom, J., Macháčková, B., Sawyer, T.K., 1996. Amoebic infections in goldfishes and granulomatous lesions. Folia Parasitol. 43, 81-90.

Edgar, R.C., 2004. MUSCLE: multiple sequence alignment with high accuracy and high throughput. Nucleic Acids Res. 32, 1792-1797.

Elder, J.F., Turner, B.J., 1995. Concerted evolution of repetitive DNA sequences in eukaryotes. Q. Rev. Biol. 70, 297-320.

Gandolfi, A., Bonilauri, P., Rossi, V., Menozzi, P., 2001. Intraindividual and intraspecies variability of ITS1 sequences in the ancient asexual Darwinula stevensoni (Crustacea: Ostracoda). Heredity 87, 449-455.

Ganley, A.R.D., Kobayashi, T., 2007. Highly efficient concerted evolution in the ribosomal DNA repeats: total rDNA repeat variation revealed by whole-genome shotgun sequence data. Genome Res. 17, 184-191.

Geisen, S., Kudryavtsev, A., Bonkowski, M., Smirnov, A., 2014. Discrepancy between species borders at morphological and molecular levels in the genus Cochliopodium (Amoebozoa, Himatismenida), with the description of Cochliopodium plurinucleolum. n. sp. Protist 165, 364-383.

Gläser, H., 1912. Untersuchungen über die Teilung einiger Amöben, zugleich ein Beitrag zur Phylogenie des Centrosoms. Arch. Protistenkd. 25, 27-152.

Gong, J., Dong, J., Liu, X., Massana, R., 2013. Extremely high copy numbers and polymorphisms of the rDNA operon estimated from single cell analysis of oligotrich and peritrich ciliates. Protist 164 , 369-379.

Gouy, M., Guindon, S., Gascuel, O., 2010. SeaView version 4: a multiplatform graphical user interface for sequence alignment and phylogenetic tree building. Mol. Biol. Evol. 27, 221-224.

Gribble, K.E., Anderson, D.M., 2007. High intraindividual, intraspecific, and interspecific variability in large subunit ribosomal DNA in the heterotrophic dinoflagellates Protoperidinium,
Diplopsalis, and Preperidinium (Dinophyceae). Phycologia 46, 315-324.

Guindon, S., Dufayard, J.F., Lefort, V., Anisimova, M., Hordijk, W., Gascuel, O., 2010. New algorithms and methods to estimate maximum-likelihood phylogenies: assessing the performance of PhyML 3.0. Syst. Biol. 59, 307-321.

Hugall, A., Stanton, J., Moritz, C., 1999. Reticulate evolution and the origins of ribosomal internal transcribed spacer diversity in apomictic Meloidogyne. Mol. Biol. Evol. 16, 157-164.

Kudryavtsev, A., 2014. Paravannella minima n. g. n. sp. (Discosea: Vannellidae) and distinction of the genera in the vannellid amoebae. Eur. J. Protistol. 50, 258-269.

Kudryavtsev, A., Pawlowski, J., 2015. Cunea n. g. (Amoebozoa: Dactylopodida) with two cryptic species isolated from different areas of the ocean. Eur. J. Protistol. 51, 197-209.

Kudryavtsev, A., Brown, M.W., Tice, A., Spiegel, F.W., Pawlowski, J., Anderson, O.R., 2014. A revision of the order Pellitida Smirnov, et al., 2011 (Amoebozoa, Discosea) based on ultrastructural and molecular evidence, with description of Endostelium crystalliferum n. sp. Protist 165, 208-229.

Kudryavtsev, A., Pawlowski, J., Hausmann, K., 2009. Description and phylogenetic relationships of Spumochlamys perforata $\mathrm{n}$. sp. and Spumochlamys bryora n. sp. (Amoebozoa, Arcellinida). J. Eukaryot. Microbiol. 56, 495-503.

Kudryavtsev, A., Wylezich, C., Pawlowski, J., 2011. Ovalopodium desertum $\mathrm{n}$. sp. and the phylogenetic relationships of Cochliopodiidae (Amoebozoa). Protist 162, 571-589.

Liao, D., 1999. Concerted evolution: molecular mechanism and biological implications. Am. J. Hum. Genet. 64, 24-30.

Long, E.O., Dawid, I.B., 1980. Repeated genes in eukaryotes. Ann. Rev. Biochem. 49, 727-764.

Maniatis, T., Fritsch, E.F., Sambrook, J., 1982. Molecular Cloning, A Laboratory Manual. Cold Spring Harbor Laboratory, Cold Spring Harbor, New York.

Miranda, L.N., Zhuang, Y., Zhang, H., Lin, S., 2012. Phylogenetic analysis guided by intragenomic SSU rDNA polymorphism refines classification of "Alexandrium tamarense" species complex. Harmful Algae 16, 35-48.

Nassonova, E., Smirnov, A., Fahrni, J., Pawlowski, J., 2010. Barcoding amoebae: comparison of SSU, ITS and COI genes as tools for molecular identification of naked lobose amoebae. Protist $161,102-115$.

Page, F.C., 1968. Generic criteria for Flabellula, Rugipes and Hyalodiscus with descriptions of species. J. Protozool. 15, 9-26.

Page, F.C., 1976. An Illustrated Key to Freshwater and Soil Amoebae with Notes on Cultivation and Ecology. Freshw. Biol. Assoc. Ambleside.

Page, F.C., 1983. Marine Gymnamoebae. Institute of Terrestrial Ecology, Cambridge.

Page, F.C., Blakey, S.M., 1979. Cell surface structure as a taxonomic character in the Thecamoebidae (Protozoa: Gymnamoebia). Zool. J. Linn. Soc. 66, 113-135.

Pawlowski, J., Audic, S., Adl, S., Bass, D., Belbahri, L., Berney, C., Bowser, S.S., Cepicka, I., Decelle, J., Dunthorn, M., FioreDonno, A.M., Gile, G.H., Holzmann, M., Jahn, R., Jirků, M., Keeling, P.J., Kostka, M., Kudryavtsev, A., Lara, E., Lukeš, J., Mann, D.G., Mitchell, E.A.D., Nitsche, F., Romeralo, M., Saunders, G.W., Simpson, A.G.B., Smirnov, A.V., Spouge, J.L., Stern, R.F., Stoeck, T., Zimmermann, J., Schindel, D., de Vargas, C., 2012. CBOL protist working group: barcoding eukaryotic rich- 
ness beyond the animal, plant, and fungal kingdoms. PLoS Biol. 10, e1001419.

Peglar, M.T., Amaral Zettler, L.A., Anderson, O.R., Nerad, T.A., Gillevet, P.M., Mullen, T.E., Frasca Jr., S., Silberman, J.D., O'Kelly, C.J., Sogin, M.L., 2003. Two new small-subunit ribosomal RNA gene lineages within the subclass Gymnamoebia. J. Eukaryot. Microbiol. 50, 224-232.

Pillet, L., Fontaine, D., Pawlowski, J., 2012. Intra-genomic ribosomal RNA polymorphism and morphological variation in Elphidium macellum suggests inter-specific hybridization in Foraminifera. PLoS One 7, e32373.

Prescott, D.M., James, T.W., 1955. Culturing of Amoeba proteus on Tetrahymena. Exp. Cell Res. 8, 256-258.

Ptáčková, E., Kostygov Yu, A., Chistyakova, L.V., Falteisek, L., Frolov, A.O., Patterson, D.J., Walker, G., Cepicka, I., 2013. Evolution of Archamoebae: morphological and molecular evidence for pelobionts including Rhizomastix, Entamoeba, Iodamoeba, and Endolimax. Protist 164, 380-410.

Rambaut, A., Suchard, M.A., Xie, D., Drummond, A.J., 2014. Tracer v1.6. Available from: http://beast.bio.ed.ac.uk/Tracer.

Ronquist, F., Teslenko, M., Van Der Mark, P., Ayres, D.L., Darling, A., Höhna, S., Larget, B., Liu, L., Suchard, M.A., Huelsenbeck, J.P., 2012. MrBayes 3.2: efficient Bayesian phylogenetic inference and model choice across a large model space. Syst. Biol. 63, 539-542.

Sawyer, T.K., 1975a. Marine amoebae from surface waters of Chincoteague Bay, Virginia: one new genus and eleven new species within the families Thecamoebidae and Hyalodiscidae. Trans. Am. Microsc. Soc. 94, 305-323.

Sawyer, T.K., 1975b. Clydonella n. g. (Amoebida: Thecamoebidae), proposed to provide an appropriate generic home for Schaeffer's marine species of Rugipes, C. vivax (Schaeffer, 1926) n. comb. Trans. Am. Microsc. Soc. 94, 395-400.
Simon, U.K., Weiss, M., 2008. Intragenomic variation of fungal ribosomal genes is higher than previously thought. Mol. Biol. Evol. 25, 2251-2254.

Sims, G.P., Rogerson, A., Aitken, R., 1999. Primary and secondary structure of the small-subunit ribosomal RNA of the naked, marine amoeba Vannella anglica: phylogenetic implications. J. Mol. Evol. 48, 740-749.

Smirnov, A.V., Brown, S., 2004. Guide to the methods of study and identification of soil gymnamoebae. Protistology 3, 148-190.

Smirnov, A.V., Nassonova, E.S., Chao, E., Cavalier-Smith, T., 2007. Phylogeny, evolution, and taxonomy of vannellid amoebae. Protist 158, 295-324.

Stamatakis, A., 2014. RAxML version 8: a tool for phylogenetic analysis and post-analysis of large phylogenies. Bioinformatics 30, 1312-1313.

Tekle, Y.I., 2014. DNA barcoding in Amoebozoa and challenges: the example of Cochliopodium. Protist 165, 473-484.

Wuyts, J., De Rijk, P., Van der Peer, Y., Pison, G., Rousseeuw, P., De Wachter, R., 2000. Comparative analysis of more than 3000 sequences reveals the existence of two pseudoknots in area V4 of eukaryotic small subunit ribosomal RNA. Nucleic Acids Res. 28, 4698-4708.

Wuyts, J., Van der Peer, Y., De Wachter, R., 2001. Distribution of substitution rates and location of insertion sites in the tertiary structure of ribosomal RNA. Nucleic Acids Res. 29, 5017-5028.

Zlatogursky, V.V., Kudryavtsev, A., Udalov, I.A., Bondarenko, N., Pawlowski, J., Smirnov, A., 2016. Genetic structure of a morphological species within the amoeba genus Korotnevella (Amoebozoa Discosea), revealed by the analysis of two genes. Eur. J. Protistol. 56, 102-111.

Zuker, M., 2003. Mfold web server for nucleic acid folding and hybridization prediction. Nucleic Acids Res. 31, 3406-3415. 